Kath Dooley

\title{
Oppositions and lines of desire: Exploring the screenwriting approach of Claire Denis in a practice-based study
}

\begin{abstract}
In her twenty-five year career, French writer/director Claire Denis has produced close to a dozen feature films. Existing in the margins of mainstream cinema, Denis's work includes disturbing and/or horrific films that explore the body as a site for identity formation, sexual debasement and transgressive urges. The majority of Denis's films have been written in collaboration with cowriter Jean-Pol Fargeau, a process Denis describes as involving the 'grafting' of various elements into a coherent whole. This approach sees character and plot defined through the drafting of a 'diagram of relations', a form of construction that distances Denis from popular approaches to screenwriting undertaken in Australia.

In this article I describe how I conducted a practical investigation of Denis's approach by writing an original 25-minute screenplay (produced into a film in early 2012). This process was both a means of further enquiry into Denis's thematic and practical concerns, and a creative outcome of my PhD research, which allowed for a reinvigoration and evaluation of my previous practice as screenwriter. The resulting script is a departure from my previous output, with a different approach to plot signifiers, conflict and the psychological representation of character. With self-reflexive examination and creative analysis, this paper explores the specifics of Denis's approach and its impact when imported into my practice in an Australian context.

Keywords: Claire Denis, screenwriting, the body
\end{abstract}

In her twenty-five year career, French writer/director Claire Denis has produced close to a dozen feature films while working in the margins of mainstream cinema. Labelled as part of the French cinema du corps (cinema of the body) trend at the beginning of the 21 st century, Denis's work includes disturbing and horrific films that explore the body as a site for identity formation, sexual debasement and transgressive urges; material rarely explored in Australian cinema. Denis's approach to screenwriting also distances her from mainstream screenwriting practices followed in Australia. Whether adapting a novel, drawing upon real events or working with themes imposed through a TV commission, the filmmaker has written the majority of her feature films in collaboration with co-writer Jean-Pol Fargeau. Denis describes their process of screenplay creation as involving the 'grafting' of various elements into a coherent whole. At the beginning stage, character and plot are defined through the drafting of a 'diagram of relations' to establish lines of desire, oppositions, immobility and/or movement (Martin 2005). Additionally, point of view conventions more commonly associated with documentary film have influenced her approach. These points of difference: firstly, Denis's thematic concerns and 
secondly, her distinct screenwriting methods, gave me reason to pause. I questioned the causality of her work; specifically, the relationship between Denis's thematic and stylistic concerns and her method of screenplay construction. Secondly, I wondered what value a practice-based study of her work could hold as a way of re-evaluating my own practice as a screenwriter. Denis's approach to screenwriting seemed to be significantly different from my own established ways of working, and therefore promised to be an exciting area for interrogation.

In this article I describe how, as an Australian screenwriter, I conducted a practical investigation of Denis's approach by writing an original 25-minute screenplay titled The Sister, which was produced into a film in early 2012 (The Sister can be viewed online at http://vimeo.com/95459616). Adopting what screenwriting theorist Steven Maras describes as a 'descriptivist or nominalist attitude' to screenplay research, the first part of this study looks at the work of Denis with the aim of shedding further light one example of 'the diversity of practices that define screenwriting' (Maras 2011: 277). In doing so, I attempt to address Adrian Martin's recently made point that 'we are only at the beginning of investigating the various kinds of texts- written, graphic, sonic, and so forththat filmmakers produce in the pre-elaboration of a film' (Martin 2014: 18). After identifying several interesting facets of Denis's approach, I attempted to emulate these in the context of my own practice in Australia, an activity with dual goals. This process was firstly a means of further enquiry into Denis's concerns, and secondly, offered a chance to re-invigorate and re-evaluate my own practice as a screenwriter. This second part of my study follows a 'practice-based' trajectory of screenwriting research, one that focuses on 'firsthand case studies', this involving my own screenwriting experiment (Maras 2011: 280). I wondered; would an emulation of Denis's techniques lead to a radical change in my work? Could such a study point out the limitations of my existing screenwriting practice? The resulting script, The Sister, was a departure from my previous output as writer, with a different approach to plot signifiers, conflict and the psychological representation of character. With self-reflexive examination and creative analysis, this article explores the specifics of Denis's approach and its impact when imported into my practice in an Australian context.

While I acknowledge Maras's suggestion that 'a more complete 'mapping' of [...] scripting practices might focus on the local screen cultures in which they emerge, and the collaborative creative context supporting them', it goes beyond the scope of this article to provide a detailed overview of French screen culture and industrial practices (Maras 2009: 3). While Denis's work has undoubtedly been shaped by these factors, my focus on practice-based research is concerned with her individual approach to the screenplay (and what it can offer when contrasted to my own approach) rather than her positioning alongside her French peers.

I will, however, situate Denis's work alongside that of other filmmakers associated with the early 21 st century cinema $d u$ corps, trend, otherwise known as the 'new French extremity'. Catherine Breillat, Gaspar Noé and Bruno Dumont are amongst the other filmmakers associated with this trend, one that presents a range of aesthetic tendencies, ranging from the 'radical selfreflexivity of the New Wave, to the focus on colour and setting in the cinéma $d u$ look, and coming back around to a radical approach of affective cinema' (Nicodemo 2013: 12). These writer/directors' careers have been informed by a trend towards internationalism and co-production, and the globalisation of film festivals and French film culture (Palmer 2006: 25). Like Denis, those cited above are filmmakers regarded as auteurs, although as Palmer notes, 'unlike the movement embodied by Godard, Truffaut, and their Cahiers du cinéma 
contemporaries ... this is a group connected more loosely, through commonalities of content and technique' (Palmer 2006: 22). One can find similarities in the group's use of explicit and transgressive imagery, and stark portrayals of the human body; however, common approaches to screenwriting are difficult to pinpoint. Breillat, for example, writes alone, and has adapted the majority of her feature film works from her own novels, in contrast to Denis. Dumont and Noé have also written the majority of their feature films alone, with little scholarly work addressing their approach to the screenplay. For all of these writer/directors, auteur status has meant the ability to develop their own individual working methods in the pre-elaboration of a film, being somewhat shielded from commercial forces and mainstream expectations. It has also meant a focus on their 'creative dominance of all phases of cinematic creation,' which Riikka Pelo describes as central to the auteur philosophy that has stemmed from the French New Wave (Pelo 2010: 115). For this reason, this article does not attempt to provide further historical or contextual insights into the cinema $d u$ corps, or to find links between the screenwriting works of its major contributors. Rather, I have focused on the specifics of Denis's individual approach to the screenplay, considering her work as 'a layered activity, drawing together skills, performance, concepts, experiences and histories' (Maras 2009: 12). By undertaking practice-based research and then critical reflection, I hope to not only reassess Denis's concerns, but to think about my own work differently in terms of my attitude to the screenplay, and assumed norms of writing.

\section{Claire Denis: Collaborative auteur}

The films of Claire Denis find their origins in a variety of public and personal places. These include written texts: Chocolat (1989)and White Material (2009) were both inspired by Doris Lessing's novel The Grass is Singing, whilst Vendredi Soir (Friday Night 2002) and L'intrus (The Intruder 2004) are adaptations of works by Emmanuèle Bernheim and Jean Luc Nancy respectively. J'ai pas Sommeil (I Can't Sleep 1994) was based upon the acts of a real life serial killer, whilst the narratives of Beau Travail (Good Work 2000) and Trouble Every Day (2001) revolve around themes imposed by a television commission [1]. Whatever her starting point, the process of script writing and film realisation seems to involve the blending of a range of ideas and influences, beginning as fragments and reworked with input/inspiration from her collaborators, literature, music, and current affairs [2]. Denis states that 'in my work I talk often about grafting. It is as if, for me, cinema is only interesting if it is grafted', a comment that strongly relates to her process of scriptwriting (quoted in Renouard \& Wajeman 2004: 23). Considering her films' focus on the surface of the skin, it is apt that Denis should choose a word with such bodily connotations to describe her practice of incorporating disparate elements into a coherent work.

Having grown up in Africa as the daughter of a French civil servant, Claire Denis's early experiences of life positioned her as an outsider. Her debut feature film Chocolat tells the story of a white couple living in a colonial African setting, no doubt influenced by these experiences and observations. In this film, Denis displays some of the thematic and stylistic tendencies of her work to come; we see an ensemble cast who gravitate towards one another in a series of dangerous intersections. With some characters enjoying only moments of fleeting contact with others, Denis's subject matter allows for exploration of foreign bodies and complex post-colonial relationships. Later films Beau Travail and Trouble Every Day tackled these themes with images of increased violence and/or horror; in these films the camera glides over the skin of Denis's 
protagonists as they engage in battle, murderous sprees or just undertake mundane daily chores. As with the writer/director's earlier works, they are light on dialogue and restrict psychological insights into character. Rather, Denis connects her players through shared gazes and moments of dangerous and/or violent bodily contact.

It would be apt to describe Denis as a collaborative writer as all of her dramatic feature film works have been co-written. She collaborated with acclaimed novelist Marie N'Diaye to write White Material (2009) and with Emmanuèle Berheim for Vendredi Soir (2002), which was based on Berheim's novel. Most notably however, screenwriter Jean-Pol Fargeau is central to Denis's collaboration, having worked with the director on nine films since her first, Chocolat, in 1988. Prior to working with Denis, Fargeau had established himself as a musician and playwright, i.e. as a professional artist/writer working outside of the film industry, which is a trait shared by all of the director's collaborators. In the press kit for 35 Rhums (Unknown 2007), Fargeau likens his collaboration with Denis to that of musicians composing an album. 'Since the start ... I always compared the excited complicity which binds us, Claire and I, to that of the musicians reunited to compose an album' (Fargeau 2007: 17). One could assume that the input offered by Fargeau and these other creatives (each with different experiences and backgrounds of writing) creates a layer of opposition in the work produced.

The use of mapping to create a web of character interaction and plot points appears to underpin the writer/director's approach to the screenplay. Adrian Martin describes the script-devising work of Denis and Fargeau as involving the creation of a 'basic network or diagram of relations', a process raising questions concerning 'what [does] each character see[s], whom [do] they look at; [what are] the lines of desire, or hatred; who tells which part of the story; significant back story elements connecting the characters in their shared or overlapping pasts; the real or imaginary status of each event' (Martin 2005). I would suggest that this particular method of construction appears to hold significant points of difference from the model promoted by mainstream screenplay manual writers, which often focuses on character objectives, obstacles and three-act structure. By contrast, Denis's approach sees plot conflicts driven by series of character oppositions, as I will go on to describe in more detail.

This is not to say that the use of mapping techniques is distinct to Denis or particularly uncommon in the creation of a screenplay. With reference to her own work, Jill Nelmes aptly makes the point that 'scene breakdowns or index cards may also be used as a way of “mapping” (a) story' (Nelmes 2008: 336). To take one example of a diagram specific approach, Denis's method holds similarities with the character-based approach of veteran British director Mike Leigh, who creates a story diagram from a web of actor improvisation and interactions [3]. The idea of a 'diagram of relations' between characters echoes Leigh's approach to the creation of drama, but unlike the British director's method of screenplay construction, this writing stage for Denis and Fargeau does not appear to involve actor improvisation in the process. All of these approaches can be viewed as examples of what Maras terms 'scripting', which may involve notation 'related to the desire to record affects, images and thoughts' (Maras 2009: 125). Likewise, they also fit within screenwriting theorist Ian MacDonald's definition of the screenplay as a 'record of an idea for a screen work' (MacDonald 2004: 89). This last description, in particular, allows for the consideration of a diverse range of practices and approaches to screenwriting. 
The specificity of the writer/director's method can be evidenced in her master classes in 'Cinema as Cultural Anthropology' at the European Graduate School, videos of which are now archived on YouTube (EGS 2010). In one of these classes, using the word 'clandestine' and the setting of a train as a starting point, Denis encourages students to explore character and point-of-view oppositions to map a film narrative. The writer/director asks students to consider whether a hypothetical film might begin inside or outside the train, whether the action unfolds in movement or a situation of immobility, and who is the watcher and who is watched? A focus on oppositions appears to underscore the development of the film narrative. As students make choices, the starting point of the film is literally mapped in a diagram on a white board.

Over the course of the EGS video lectures, Denis often returns to the idea of risk-taking in regards to character oppositions and point of view. She voices her preference for documentaries (which she has also written and directed) that bring viewers into proximity with characters without relying on voice over or other narration to make a point. 'As audience you just exist with them... you have to accept the duration of time you spend with characters. Every noise, response, action, tells you about them' (Denis quoted in EGS 2010). This preference is evident in Denis's fictional feature film work, which features a clear focus on character physicality and carefully selected point of view, rather than plot, as the driver of her films. For example, films such as Vendredi Soir and 35 Rhums capture the moment-to-moment movements of protagonists and are often shot in long-takes, with slight plot developments bringing each film to a climax. For the director, the perfect point of view is one without judgement, a concept realised in her feature film work (Morrey 2008: 30). Preferring to take a light-handed approach to story, the writer/director allows camera positioning and point of view to establish the trajectory of the narrative without foreshadowing events to come. As Denis remarks, 'there is incredible suspense when you are with someone and you don't know where they are going' (EGS 2010).

Returning to the 'diagram of relations', Martin notes that, 'once this template, with its logic, is in place, Denis's work as an artist seems to involve a process of complicating that network, confounding it, punching holes in it, making it mysterious' (Martin 2005). This process, which begins at script stage and continues into postproduction, has the result of making the audience work to connect elements during the viewing experience. One can, for example, observe several story ellipses in the narrative of L'intrus (the actual heart transplant) and 35 Rhums (the marriage proposal). The scriptwriting process of Beau Travail further illustrates the process by which Denis 'confounds' the narrative. After deciding upon a story concerning the French Foreign Legion in Djibouti, Denis and Fargeau set about writing 'journals' for the fictional main character, Galoup. Loosely based on the short story Billy Budd, these journals were read by lead actor Denis Lavant and by director of the fiction unit of Arte TV, Pierre Chevalier, to provide insight into the project. Denis describes the process: 'Pierre Chevalier told me at one point that I had to produce a screenplay. But I did not know how I could do so and still stay with the idea of the journal. So we made the journal into the beginning of a screenplay, and we produced a second part in counterpoint' (quoted in Castanet 2004: 145). This statement suggests the grafting of separate texts into a completed screenplay, with a strong focus on Galoup's point of view from the journal element. James Williams notes that the screenplay 'in turn operated in counterpoint with the voiceover Denis wrote based on her memory of watching Le Petit Soldat (The Little Soldier)', the 1960 Jean-Luc Godard film that also focused on the Foreign Legion. Combined with actor movement devised with choreographer Bernardo Montet, 'this working method formed a kind of musical "hybrid-graft" ' (Williams 2004: 49). The meshing of material, the references to past works and the gaps in the story, not 
only suggest innovation on Denis's part, but also requires the viewer to invest heavily in order to piece together the various elements of the work.

Perhaps the most convincing evidence of Denis's collaborative approach to screenplay writing can be derived from her comments about the finished product: 'I don't at all like the idea of a screenplay being a cage and that inside the cage you have to direct the actors. It seems to me that a screenplay is a kind of take-off and that the best moment is to see the characters taking off' (quoted in Ancian 2002). This returns us to the concept of grafting, which here describes an opportunity for actors to take charge of the written material and integrate their own personal experiences and association with previous film works into their selected roles. As Adam Ganz suggests, 'it is the nature of storytelling to improvise, to patch together, to juxtapose, in order to make its meanings', a process that appears to continue during the preproduction and production of Denis's work (Ganz 2012: 84).

My research into Denis's approach raised several questions for my own practice as a screenwriter in Australia. How could an emulation of the thematic, stylistic and practical concerns of this filmmaker inform the writing of my own short film screenplay? What potential value could her approach hold as a starting point for an invigorated and different mode of writing and screen production? Specifically, I was interested in exploring the extent to which the writer/director's method of writing fostered the eventual style of narrative created. With these questions in mind, I undertook a practical investigation of Denis' approach in the writing of a twenty-five minute screenplay, The Sister, in late 2011. I hoped to learn more about the specifics of Denis's approach through the action of screenwriting: practice as research, informed by prior research into primary and secondary sources. This creative research would function as a means of further exploration of Denis' practice and of comparison with my established habits of screenwriting, which could not otherwise be achieved. Budget constraints relating to the eventual production of my project meant that I was limited to a project of short film length, and whilst I acknowledge that the writing of a feature film script may have allowed for increased insight into Denis's work as an artist, I feel that the twenty-five minute film was nonetheless a successful means of exploration. The completed screenplay has the tangible outcome of being a vehicle for critical discourse on the concerns of Denis, and on my own concerns as a writer/director. I must note that, with myself in the role of director, The Sister was produced in early 2012 as part of my practice-informed $\mathrm{PhD}$, however; I will maintain a focus on the written screenplay text within this article.

Before detailing the changes in my writing practice brought about when undertaking The Sister, I will first briefly address my previously established ways of working. My approach to the screenplay has been shaped by my Australian tertiary education in Screen Arts, by participation in script development and pitching programs run by both UK and Australian development bodies (development labs and more personal one-on-one experiences with script editors), and by the submission of my work to such bodies. Ian Macdonald describes the process of 'how individuals form a system of dispositions within a culture and area of activity' according to Pierre Bourdieu's concept of 'habitus,' which, in terms of screenwriting 'provides the practice with its normative codes, which are (re-) internalised as 'best practice,' craft skills and so on' (Macdonald 2010: 46). In this sense, my screenplays have been informed by the above experiences, and by the writings of institutionally sanctioned screenwriting gurus such as Robert McKee and Michael Hague, both of who follow a conflict-resolution model of writing. As a filmmaker who has yet to have a feature film produced, I am not recognised as an auteur (and nor to I consider myself one). I have therefore felt a reasonable 
amount of pressure to follow these mainstream writing styles in order to progress with the development of my projects. As such, I feel that my screenwriting has been most clearly aligned with a Hollywood cinema model. Bordwell, Thompson and Staiger note that, from the outset, basic principles of Hollywood film practice have included 'the story as the basis of the film, the technique as an "indiscernible thread," the audience as controlled and comprehending, and complete closure at the end of all' (Bordwell, Thompson \& Staiger 1985: 195). I believe that, as an independent Australian writer/director seeking the support of government agencies, I have been encouraged to produce work, and I have produced work underpinned by these same principles. Prior to undertaking the study detailed in the article, my method had involved the careful conjuring of a feature film premise and logline based on the conflict-resolution model, which had then been expanded to a synopsis, outline and then full script. I had taken three unproduced feature film scripts and several produced short films through this process of development. I do not wish to claim that my approach to screenwriting is typically 'Australian' as such a statement could only be based upon further research into the diversity of practices that exist in my home country. Rather, I present an overview of my influences in an Australian cultural and industrial context, so as to provide insight into my personal methods of working.

I had, however, often contemplated what Kathryn Millard describes as 'the preplanned, conflict-driven Story, evangelised in texts and seminars around the globe, (which) points towards a narrow and overly prescriptive conception of cinema' (Millard 2006). Millard, citing Gus Van Sant, Jim Jarmusch, Chantal Ackerman and many others as examples, notes elsewhere, 'the work of many innovative screenwriters and film-makers has long favoured audio and visual expressivity over plot and narrative drive' (Millard 2010: 13). I would add Claire Denis to Millard's list, due to the writer/director's focus on character physicality, rather than just character psychology, as the driver of her films. Her approach seems less concerned with journey and more on character contrasts as a way of generating drama. Differences in status, behaviours and positioning in relation to social standing and class, all determine character wants and needs in Denis's films, which may well lead to conflict, meaning plot developments as a consequence. Writing on American independent cinema, film-maker and screenwriting theorist JJ Murphy suggests, 'real innovation in screenwriting ... comes not from ignorance of narrative film conventions but from being able to see beyond their limitations' (Murphy 2007: 266). Reflecting on these points, I identified the approach of Denis as one that, if adopted as a means of exploration in the writing of The Sister, offered a means to explore the limitations of my own established practice. Denis's approach therefore, cannot be considered an 'alternative' to Australian practices as a whole, and rather, my concern is with its variation when compared to my own individual approach.

I wish to be clear, also, that I did not seek to emulate every aspect of Denis's process, and most notably, I did not co-write the screenplay for The Sister. While the issue of how to overcome established writing habits limiting or negatively influencing the new project was of concern, I did not have a person outside of the film industry available for collaboration, as is Denis's method. Rather, the script of The Sister was developed with the input of four actors (students at the Flinders University Drama Centre) who would go on to play the lead roles in the film, using the concepts of 'grafting' and a 'diagram of relations' as starting points [4]. All four individuals generated ideas in relation to character development, which were integrated into a cohesive whole. As well as injecting new perspectives into the 'diagram of relations' that would become a script, this collaboration allowed me to take a step back and evaluate my own practice; a sort of defamiliarisation and rediscovery where 'the artist intuitively adopts dual roles of the researcher and the researched, and the process changes 
both perspectives because creative and critical inquiry is a reflective process' (Sullivan quoted in Smith \& Dean 2009: 51).

\section{The process of mapping: The Sister}

I will now describe the process of writing The Sister, from the initial generation of ideas as starting point, to the grafting of character and plot elements using the 'diagram of relations' approach. At the beginning of the script devising process, all four of my prospective actors were unknown to me. This is somewhat contrary to the approach of Denis, who has had repeated collaboration with a 'family' of actors with whom she is well acquainted. Wanting to align myself with this tendency, I decided to spend some time observing the four individuals in acting classes at Flinders University, and to undergo short interviews in order to get a sense of their respective skill sets. After several observations, I asked the four to speak to the camera about an incident involving bodily discomfort and/or their bodily experience (see Figure 1 ); these were responses to one or two specific questions shaped by a list of Denis's identified thematic concerns. I hoped that such an activity could generate interest in a particular area, perhaps leading to a definitive starting point. I also wished to acknowledge the actors' minds and bodies as storehouses of memory and experience, which could be brought into play in the writing process. The responses to the questions were varied. Sarah Allen spoke of an incident when she was unable to stop fidgeting, whilst Lochlin Maybury spoke of his experience of a broken collarbone. Rhiannon Williams described episodes of 'sleep talking,' and James Smith recalled a temporary facial disfigurement experienced as a child [5]. All were sound potential starting points for a screenplay.

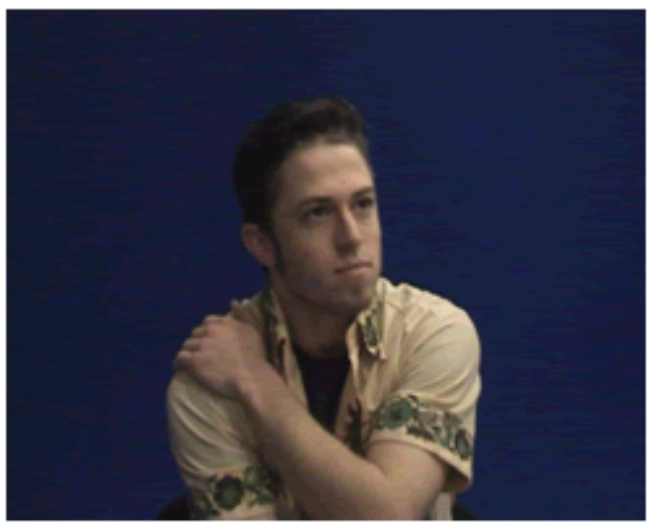

James Smith

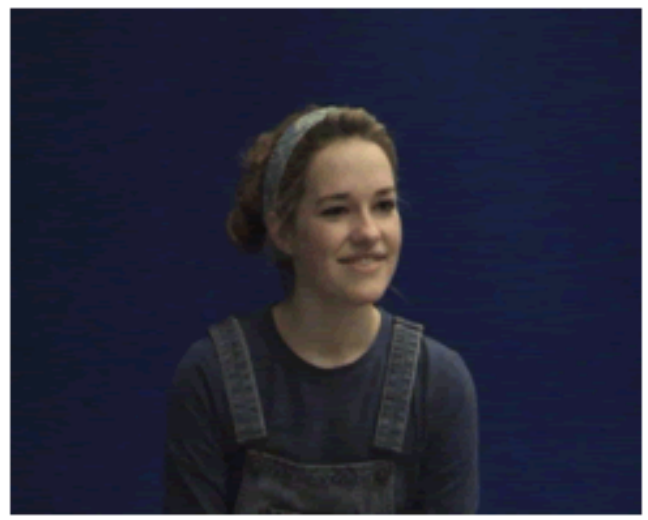

Sarah Allen

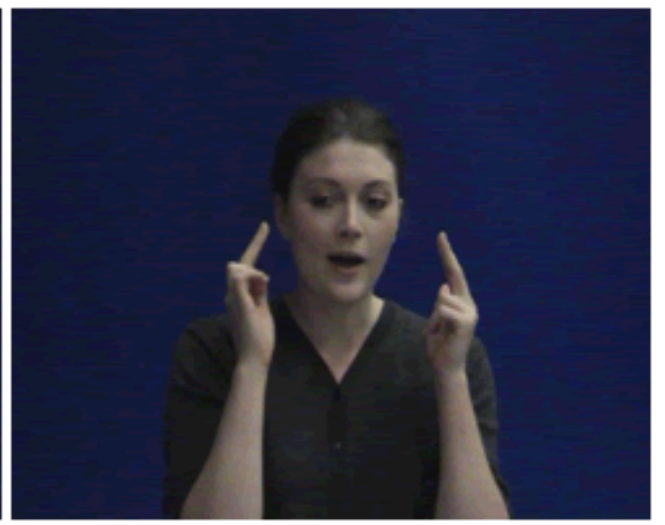

Rhiannon Williams

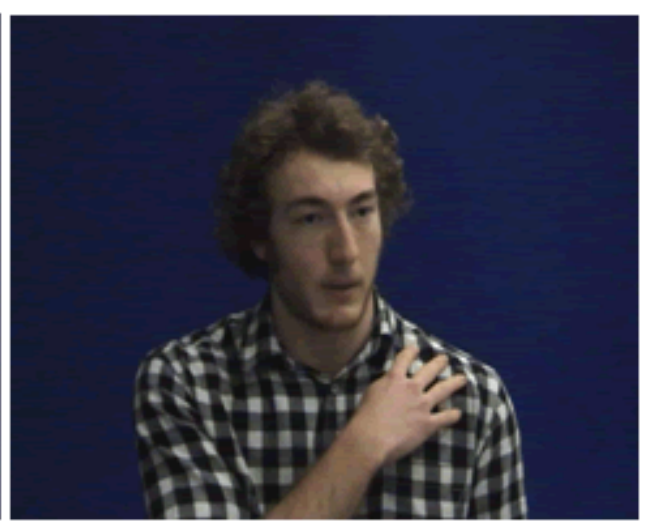

Lochlin Maybury

Figure 1: Introduction to the actors - questions on camera. 
Initially a number of potential characters for The Sister were developed as unconnected entities. Although only one character per actor would eventually be utilised, this development process meant more initial possibilities and a process of elimination. My task then turned to decisions on how they could relate to one another. How could I graft these different characters and pieces of backstory into a coherent narrative? The Denis/Fargeau method of constructing a 'diagram of relations' provided a means to achieve this. As described previously, this method of mapping is driven by a series of questions to determine character positions, relationships, point of view and the revelation of plot. Working around a particular theme, pertinent questions include:

Who is on the inside/outside?

Who is the watcher and who is watched?

Who is in motion/who is immobile?

What are the lines of hate and desire?

What is the shared back-story?

Who reveals these elements of back-story?

What is real/imagined?

This method of mapping identifies a series of oppositions, which leads to the creation of drama. Character oppositions facilitate the exploration of foreign bodies, dangerous contact and/or intersections, all key concepts in Denis's work. As I have noted, the director emphasises the physicality of her characters, rather than their psychology, sometimes leaving questions concerning motivations for actions unanswered. With this in mind I mapped a series of diagrams with the inclusion of character material drawn from the four actors. Character back-stories were shared to create common histories and narrative crossovers. It soon became clear that the concepts of 'intersecting lives' and 'dangerous contact' worked across a range of scenarios for script development. By placing characters in emotional, social and/or physical opposition, it was somewhat natural that they should eventually intersect, with potentially disturbing results. With this noted, I arrived at a final arrangement (see Figure 2). 

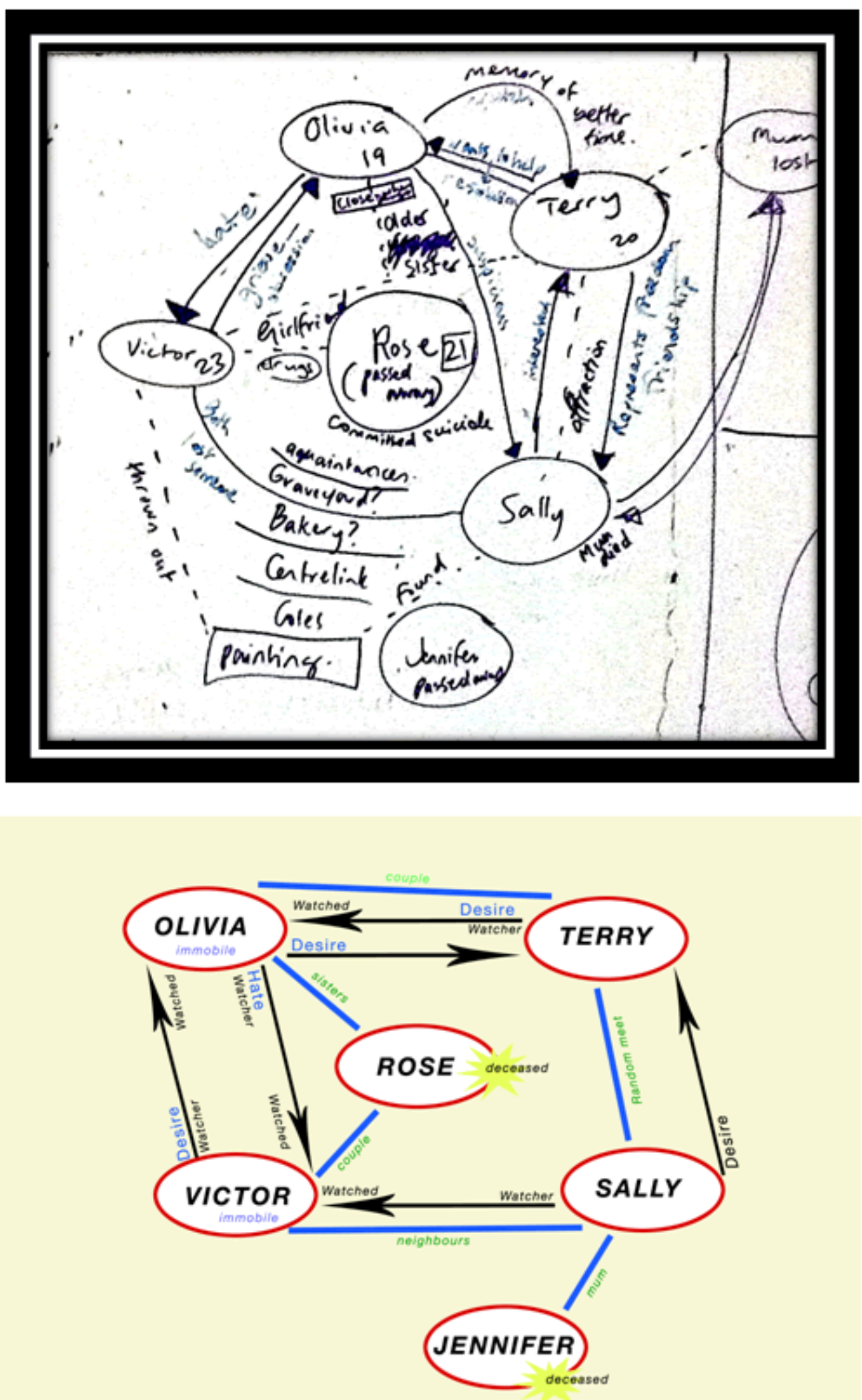

Figure 2: The diagram of relations, workshopped on a classroom whiteboard, then summarised more clearly.

Each of the circles in the diagram above represent a character, with the four lead actors to play the parts of Victor (James Smith), Olivia (Rhiannon Williams), Terry (Lochlin Maybury) and Sally (Sarah Allen). Other characters associated with individual back-stories were woven into the diagram. It is important to point out that the centrally placed character, Rose, andJennifer(bottom centre) are deceased, but that others' memories of them 
play important roles in shaping the story. In discussion with the four actors, I linked the characters Victor and Olivia to a girl that had tragically drowned a year earlier (Rose). Victor was Rose's boyfriend, whilst Olivia was her sister. Neither had properly moved on with their life in the year since Rose's death. Terry became Olivia's boyfriend, whilst Sally was a less inhibited girl with whom Victor becomes involved.Both Olivia and Victor are unable to move forward with their lives; their film journey would be redemptive by means of sharing their grief. By contrast, Sally is moving forward, having recovered from the loss her mother, Jennifer, several years earlier. Returning to the questions listed above, one can note that the arrows moving from one character to the next indicate lines of desire and/or hatred, enabling the creation of plot. Victor was the most obvious outsider in the diagram, a young man who would observe Olivia from a distance, just as she too could spend time watching him. Victor and Olivia would also be immobile characters, as if their lives had stopped moving forward following the death of Rose. Terry was to be the concerned watcher of Olivia, whilst Sally, as complete outsider, observed much of the action from a more distanced position.

With this diagram as a guide, I went away and wrote the screenplay for The Sister. This stage involved the transferral of the mapping undertaken with the four actors into standard script layout so that it could be utilised and understood by the film crew at production time. My desire at this point was to resist my learned and hard-wired tendency to conform to conventions involving character journey, story structure and closure, and rather, to let Denis's questions guide the action. Instead of considering character trajectory and resolution as I had in the past, I focused on a change from character and/or plot immobility to movement, from characters' shift of sentiments from hate to desire and from their positioning as watcher to watched (or vice-versa). I had previously revealed character through action directly related to plot, an approach linked to the belief that story is the basis of the film. For Denis, character is sometimes revealed through human movement alone; audiences need time to exist alongside the characters, and in her work these elements contribute to her nonjudgemental point of view. For these reasons, I included scenes where the characters simply existed in their own space, something that I would have considered uneconomical in my previous practice. I retained several lines of dialogue devised by the actors themselves, which contributed to the different voice of each character, rather than my voice (as writer) deciding their tones.

A short synopsis of The Sister is as follows:

Tragedy mars a lively suburban beach party when a young woman, Rose, is found drowned on the nearby beach in the early hours of the morning.

One year later 20-year-old university student, Olivia, is struggling to come to terms with her sister's death. Her frustrated partner Terry finds himself increasingly unable to guard against her waves of anger, grief and bitterness.

When Olivia unexpectedly finds herself face to face with Victor, the young man she considers to blame for her sister's death, she is forced to re-examine and deal with her suspicions. Her actions drive Terry away, and instead Victor, the deceased Rose's former boyfriend, becomes the dark focus of Olivia's daily existence.

It soon becomes clear that the similarly angry and confused Victor reciprocates this strange fascination, leading to a 
dangerous confrontation in which the details surrounding

Rose's death are finally revealed.

\section{The completed screenplay}

Perhaps unsurprisingly, the screenplay for The Sister (as well as the later produced film)is significant it its reflection of Denis's stylistic and thematic concerns. Martine Beugnet aptly describes Denis's narrative threads as embodying 'the erased traces of a repressed past' which 'constantly threaten to resurface, and cyclically, mysteriously, as in a traumatic expression of forgotten memories, violently erupt' (Beugnet 2004: 20). This statement makes reference to an over arching theme in Denis's films: the influence of past trauma on present relations, which can also be considered a key theme of The Sister. Essentially, the short film is a story about grief, and specifically, about two people reconciling their feelings of loss. The central question of what happened on the night of Rose's death guides the action surrounding the crossovers of the four lead characters. The narrative moves towards the inevitable intersection of Olivia and Victor with the lead up creating ambiguity as to whether this meeting will involve violence. The back-story of Rose's death is also ambiguous, so that Victor may be thought of as a threat, even though he is ultimately not one. Like much of Denis's work, the script jumps between past and present to reveal pieces of back-story. Generally speaking, the action of the piece revolves around the intersections of characters, with a specific focus on the physicality of body and the surface of the skin (see Figure 3).
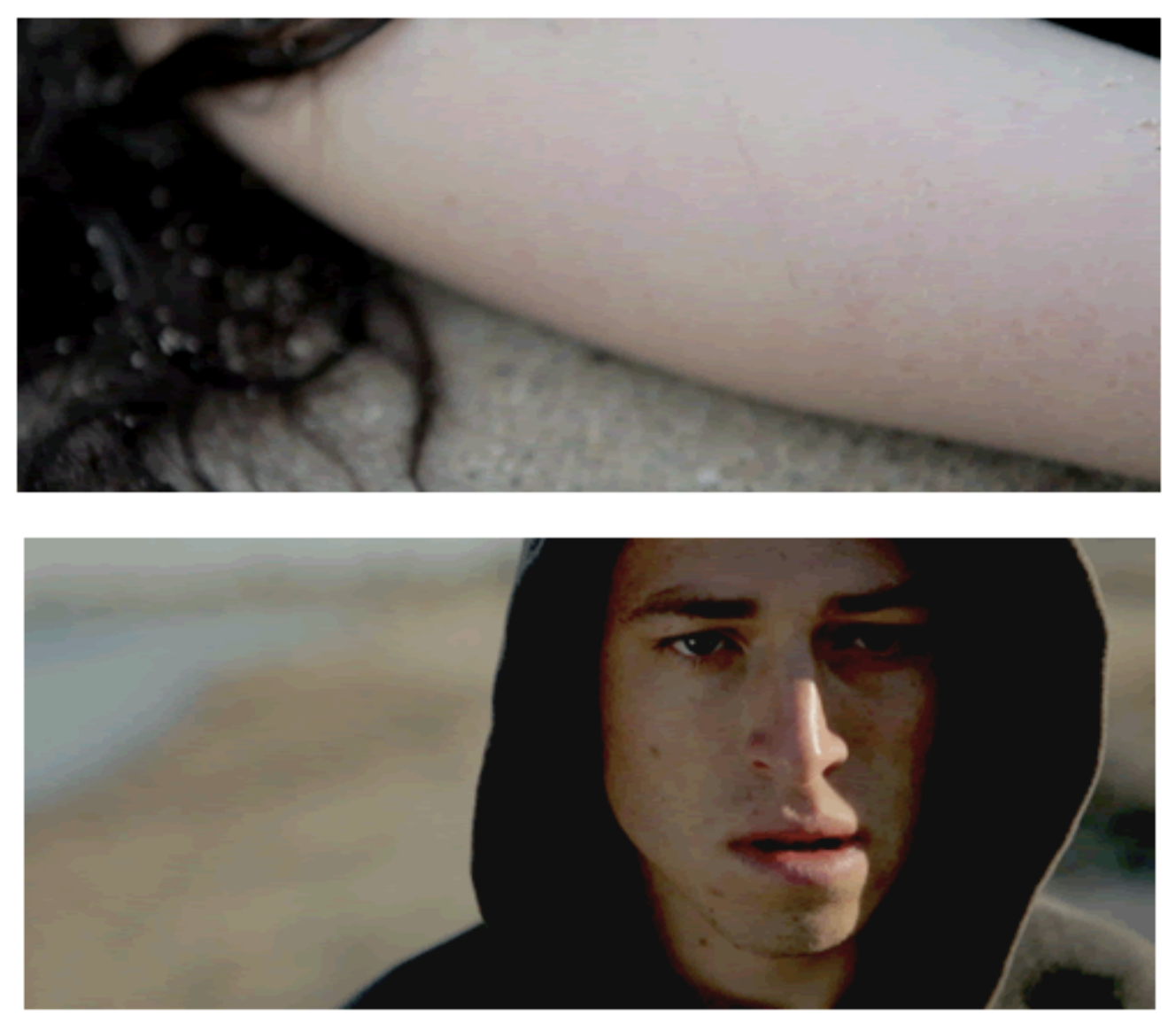

Figure 3: Victor finds Rose's body on the beach - stills from The Sister. 
Evaluating the two objectives of this study, I note that firstly, as a creative artefact, The Sister allows for greater understanding of Denis's concerns and the causality of her work. The use of the writer/director's scriptwriting approach has allowed me greater insight into her portrayal of characters on screen; namely, the importance of the physicality of the body and the power of the gaze as creators (and manifestations) of tension and conflict. I have come to realise that the 'diagram of relations' method of story construction is the cornerstone of the director's approach to thematic and stylistic concerns. I am certain that Denis's method of devising, and specifically, her method of positioning of characters in relation to one another, fosters the idea of a point of view without judgement, enabling an 'ethical representation' of film subjects. The posing of questions such as: who is in movement/immobile, or who is on the outside/inside, emphasises the placement and action of the body, rather than character psychology. As a result of my focus on character oppositions in The Sister, I have created a film in which the intersection of various characters is the key generator of both suspense and drama. There is little action and few plot points propelling the story forward. Rather, for the four protagonists, the film journey shows an acknowledgement of their selves and situations when faced with an opposing other.

Of all of the questions posed when constructing the 'diagram of relations' for The Sister, that concerning who is the watcher/watched seems key to fostering a non-judgemental point of view. I'll use the interaction of Victor and Olivia as example here. Their initial accidental meeting in a supermarket sees an exchange of hostile and frightened glances, from which Olivia flees (see Figure 4). Later scenes involve the two characters alternating in the position of watcher/watched: at a skate park, and at Olivia's apartment, but it is not until the script's climatic river side scene (a final, violent confrontation) that Victor and Olivia finally speak to one another. At this moment Olivia finally holds Victor's gaze, and he hers (see Figure 5). Accepting the gaze, so that both characters acknowledge one another, is key in the resolution of their relationship and emotional arcs. In all of these moments, dialogue is minimal or non-existent. The use of Denis's approach to writing has meant the creation of a work in which glances are more heavily implicated as a means of communicating motivations, emotions and desires.

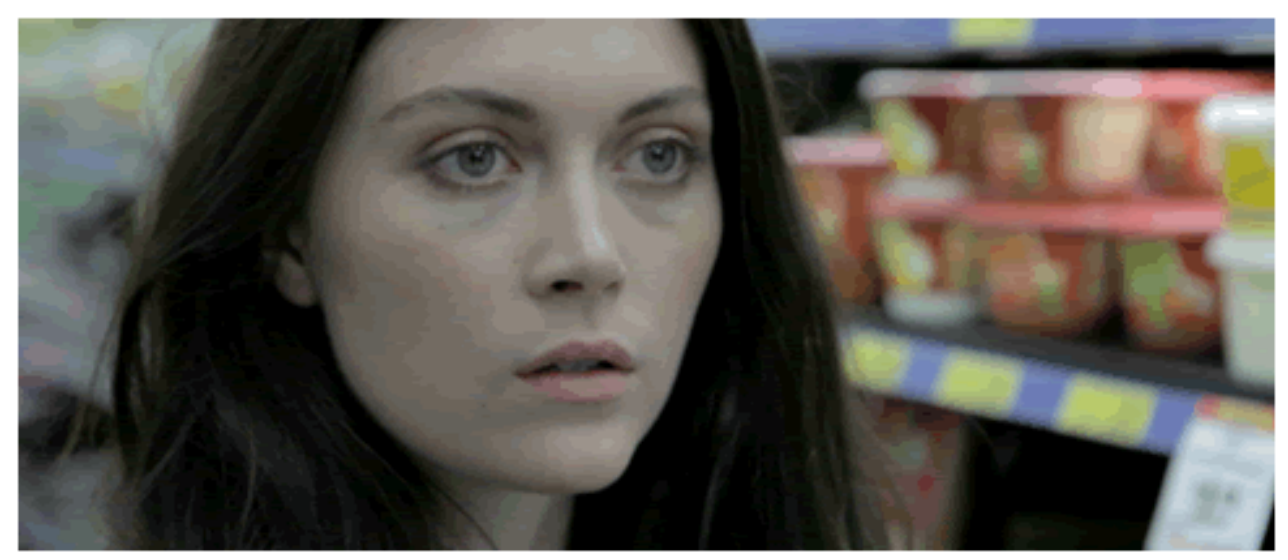




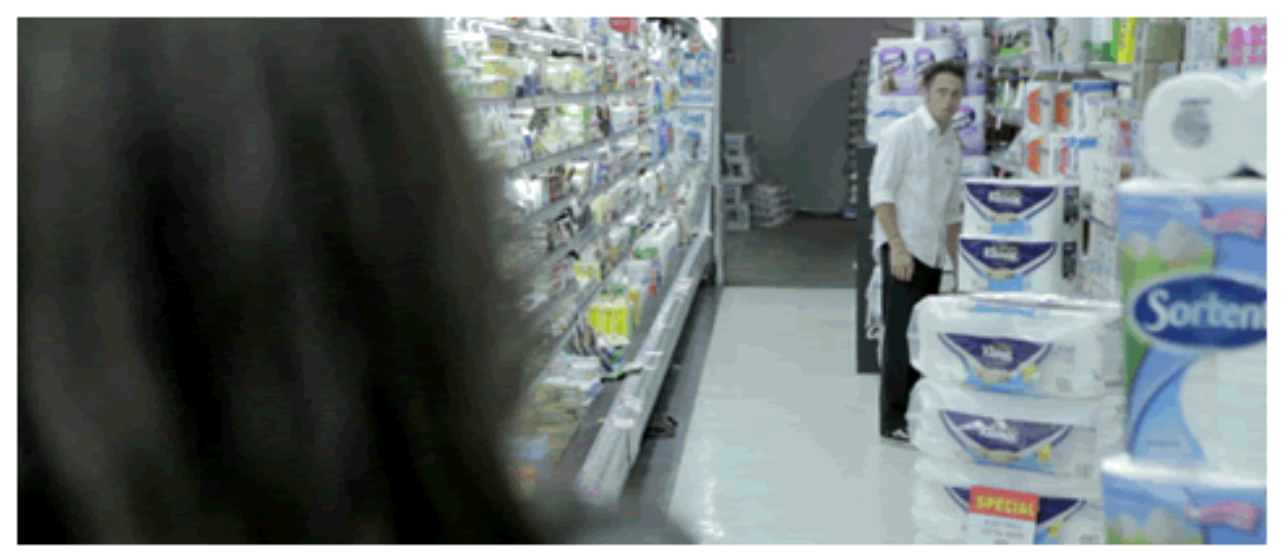

Figure 4: Olivia and Victor exchange glances without dialogue - stills from The Sister.

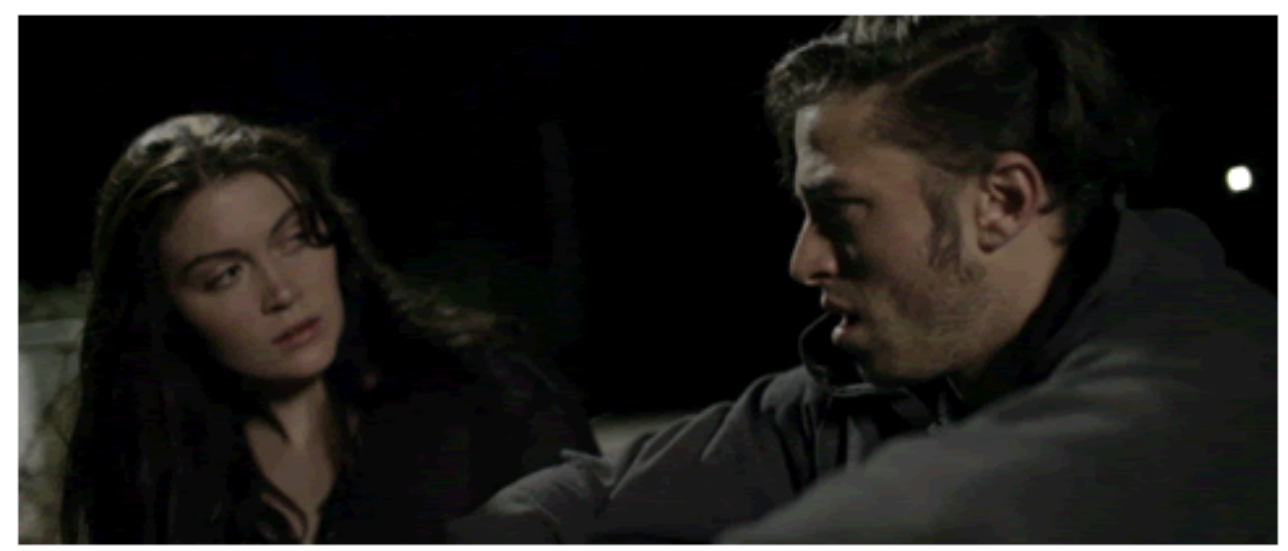

Figure 5: Olivia and Victor finally hold one another's gaze - still from The Sister.

Secondly, the undertaking of this study has indeed led to a reinvigoration and re-evaluation of my own practice. I have found Denis's approach to offer a most productive method for the construction of a film narrative. In script form, The Sister has less dialogue than my previous screenplays while featuring more characters. I must note, however, that there are some parallels when considering the 'diagram of relations' approach alongside other methods of writing and analysing a screenplay. Character oppositions in some way resemble what I would have previously termed as 'obstacles', while the lines of desire/hatred could be viewed as character 'motivation'. I am certain that if I analysed The Sister in terms of three act structure and/or turning points, I would find that these do in fact exist, although perhaps with a greater degree of ambiguity. Denis's differing approach has been useful in clarifying these points and increasing my general understanding of the principles of screenplay writing.

As a result of utilising a 'diagram of relations' as starting point, The Sister is a departure from my previous output as writer/director, with a different approach to plot signifiers, conflict and the psychological representation of character. My choice of themes drawn from the Denis's film works; of unstable and foreign bodies, has not resulted in such graphic images as those associated with the cinema du corps, a fact that reflects my own sensibilities as writer. In contrast with my previous film works, however, I feel that The Sister encourages a potentially different, and more open-ended viewing experience. By creating ambiguity in regards to character relations and back-story, rather than clearly 
signposting events within the film (as was my previous practice), there is more room for audience interpretation of the narrative. As with the privileging of glances over dialogue, the audience must therefore take a more active role in piecing the story together, rather than all the answers being provided. As this ambiguity in regards to film narrative exists as a key feature of Denis's work, I believe it apt to conclude that the concept of a 'diagram of relations' as a tool for mapping a screenplay is highly implicated in this outcome. The use of Denis's approach offers a means for re-evaluating the relationship between author, text and audience, in terms of what is offered within a screenplay and the meanings that can be created as a result.

\section{Conclusion}

Despite the influence of Denis, The Sister is a film that feels as much like 'my work' as the films I had previously written and directed. The opportunity to produce a film within the context of a PhD study has meant that I have been able to cast away the usual restraints associated with industrial expectations, so that in a sense, the film could be considered as more faithful to original ideas, and less constrained by external influences than my previous efforts. By 'constrained' I mean that the script was not taken through a development process with a third party, and that market forces related to funding, film festivals and other competitions were not foregrounded during the writing and production processes. Working with this new found freedom, I have enjoyed the opportunities for increased character and plot complexity that have come as a result of a twenty-five minute running time (more than double the length of any of my previously written short films). I have also felt extremely comfortable writing a screenplay that takes representations of the body- character physicality and interactions - as its primary focus, leaving story/plot as a secondary concern.

The study of Denis's films and the consequent emulation of her screenplay writing concerns as a method of discovery has fostered a significant change to my own practice as a writer/director. The question remains as to how I will go forward as a film practitioner? How to draw upon, or to incorporate in a sustained way some of the more exciting and innovative approaches of Denis into my future projects as writer/director? This experience will undoubtedly influence my future work; however, I acknowledge the fact that, working outside of a tertiary environment, industrial forces would make it difficult for me to fund and/or undertake a project with a similar focus, and of a similar length, a second time. I believe, however, that the ability to utilise a range of working methods and approaches when creating film projects is vital in the pursuit of dynamic imagery and screen concepts.

\section{Notes}

[1] The character of Camille in J'ai pas sommeil is based on Thierry Paulin, a young French serial killer who strangled or suffocated several elderly women in their apartments in the 1980s. return to text

[2] In a 2011 EGS Video 'Claire Denis, Scriptwriting,' Denis comments, 'I never analyse my approach to fiction. I like it when (the subject) comes to me in a very hazardous way. It's a small element of ordinary life... At the beginning it's fragments.' http://www.youtube.com/watch?v=zSL7swYwwqE return to text

[3] Mike Leigh's method of feature film 'writing' involves long periods of improvisation with several actors. After observing a series of solo improvisations by actors in various characters, 
Leigh encourages them into duo or group improvisations. From this work, relationships are established and conflicts then determine the plot of each film (Carney \& Quart 2000). return to text

[4] Collaboration with the Flinders University Drama Centre meant that the actors involved in my film project were predetermined and predated the formation of the screenplay. return to text

[5] The names and images of Sarah Allen, Lochlin Maybury, James Smith and Rhiannon Williams appear in this article with their permission. return to text

\section{Works cited}

Ancian, A 2002 'Claire Denis: An Interview', Senses of Cinema, 23:

http://sensesofcinema.com/2002/spotlight-claire-denis/denis_interview/ (accessed 12th

September 2014) return to text

Beugnet, M 2004 Claire Denis, Manchester University Press, Manchester return to text

Bordwell, D, J Staiger \& K Thompson 1985 The classical Hollywood cinema: Film style and mode of production to 1960, Columbia University Press, New York return to text

Carney, R \& L Quart 2000 The Films of Mike Leigh, Cambridge University Press, Cambridge return to text

Castanet, D 2004 'Interview with Claire Denis', Journal of European Studies, 34: 143-160

return to text

EGS 2010 'Claire Denis - Fiction, Documentary and perspective', European Graduate School: https://www.youtube.com/watch?v=JtU7MGAc-ko\&feature=relmfu (accessed 10 March 2012) return to text

Ganz, A 2012. 'Leaping broken narration': ballads, oral storytelling and the cinema', in L

Khatib (ed) Storytelling in World Cinema, Vol. 1, Columbia University Press, New York: 71-88 return to text

MacDonald, I 2010 'So It's Not Suprising I'm Neurotic: The Screenwriter and the Screen Idea Work Group', Journal of Screenwriting 1, 1: 45-58 return to text

MacDonald, IW 2004 'Disentangling the Screen Idea', Journal of Media Practice 5: 89-99 return to text

Maras, S 2009 Screenwriting: history, theory and practice, Wallflower Press, London return to text

Maras, S 2011 'Some attitudes and trajectories in screenwriting research', Journal of Screenwriting 2, 2: 275-286 return to text

Martin, A 2005 'Ticket to ride: Claire Denis and the cinema of the body':

http://www.latrobe.edu.au/screeningthepast/20/claire-denis.html (accessed 16 February 2011) return to text

Martin, A 2014 'Where do cinematic ideas come from?', Journal of Screenwriting 5, 1: 9- 26 return to text

Millard, K 2006 'Writing for the screen: beyond the gospel of story', Scan 3, 2:

http://www.scan.net.au/scan/journal/display.php?journal_id=77 (accessed 16 June 2014) return to text

Millard, K 2010 'After the Typewriter: the Screenplay in a Digital Era', Journal of Screenwriting 1, 1: 11-25 return to text

Morrey, D 2008 'Open Wounds: Body and Image in Jean-Luc Nancy and Claire Denis', Film Philosophy 12, 1: 10-31 return to text 
Murphy, JJ 2007 Me and You and Memento and Fargo: How Independent Screenplays Work, Continuum, New York return to text

Nelmes, J 2008 'Developing the Screenplay Wingwalking: An Analysis of the Writing and Rewriting Process', Journal of British Cinema and Television 5, 2: 335-352 return to text

Nicodemo, T 2013 The New French Extremity: Bruno Dumont and Gaspar Noé, France's Contemporary Zeitgeist, Doctoral dissertation, The University of Western Ontario, London ON return to text

Palmer, T 2006 'Style and sensation in the contemporary French cinema of the body', Journal of Film and Video 53, 3: 22-32 return to text

Pelo, R 2010 'Tonino Guerra: the screenwriter as a narrative technician or as a poet of images? Authorship and method in the writer/director relationship', Journal of Screenwriting 1, 1: 113129 return to text

Renouard, J \& L Wajeman 2004 'The Weight of the Here and Now: Conversation with Claire Denis', Journal of European Studies 34: 19-34 return to text

Smith, H \& R Dean 2009 Practice-led research, Research-led Practice in the Creative Arts, Edinburgh University Press, Edinburgh return to text

Unknown 200735 Rhums, Dossier de Presse (Press Kit), Soudaine Company, Paris return to text

Williams, J 2004 'O Heave! O Heave Away, Heave! O Heave!' Journal of European Studies 34, 1-2: 44-59 return to text

Dr Kath Dooley is a filmmaker and researcher based at Flinders University, South Australia

\section{TEXT}

Vol 18 No 2 October 2014

http://www.textjournal.com.au

General Editor: Nigel Krauth. Editors: Kevin Brophy, Enza Gandolfo \&

Linda Weste

text@textjournal.com.au 